\title{
Addressing Concerns about Changing the Route of Antimicrobial Administration from Intravenous to Oral in Adult Inpatients
}

\author{
Lizanne Béïque and Rosemary Zvonar
}

\begin{abstract}
Background: Many health care institutions are in the process of establishing antimicrobial stewardship programs. Changing the route of administration of antimicrobial agents from intravenous to oral (IV to PO) is a simple, well-recognized intervention that is often part of an antimicrobial stewardship program. However, the attending health care team may have concerns about making this switch.

Objectives: To provide insights into common concerns related to IV to PO conversion, with the aim of helping antimicrobial stewardship teams to address them.

Data Sources: Published clinical trials and reviews were identified from a literature search of Ovid MEDLINE with the keywords (step down or switch or conversion or transition or sequential) and (antibiotics or antibacterial agents or antimicrobial or anti-infective agents).

Data Synthesis: The following issues are addressed in this review: benefits of the oral route, serum concentrations yielded by the oral formulation, source of pharmacokinetic data, clinical outcomes, provision of care in the intensive care unit, fear of therapeutic failure, and administration of antimicrobials via feeding tube.

Conclusions: When considering a change to oral therapy, it is important to have a thorough understanding of key aspects of the antimicrobial agent, the patient, and the disease being treated. The antimicrobial stewardship team has an important role in facilitating IV to PO conversion, educating prescribers, and addressing any concerns or reservations that may interfere with timely transition from IV to PO administration.
\end{abstract}

Keywords: antimicrobials, antimicrobial stewardship programs, step-down, IV to PO transition, oral therapy, intravenous therapy

Can J Hosp Pharm. 2015;68(4):318-26

\section{RÉSUMÉ}

Contexte : Bon nombre d'établissements de santé sont en voie de mettre en place de programmes de gestion responsable des antimicrobiens. Changer de voie d'administration des agents antimicrobiens en passant d'une administration intraveineuse à une administration orale est une intervention simple et reconnue qui fait souvent partie de ces programmes. Cependant, opérer un tel changement pourrait soulever des préoccupations chez les membres de l'équipe de soins de santé traitante.

Objectifs : Dégager une meilleure compréhension des préoccupations courantes entourant le passage de la voie d'administration intraveineuse à la voie d'administration orale dans le but d'aider les équipes de gestion responsable des antimicrobiens à y répondre.

Sources des données : Des analyses documentaires ainsi que des essais cliniques publiés ont été recensés grâce à une recherche dans Ovid MEDLINE à l'aide des mots clés (step down [passage] ou switch [échange] ou conversion [conversion] ou transition [transition] ou sequential [successif]) et (antibiotics [antibiotiques]) ou antibacterial agents [agents antibactériens] ou antimicrobial [antimicrobien] ou anti-infective agents [agents anti-infectieux]).

Synthèse des données : Les préoccupations suivantes sont abordées dans la présente analyse : les avantages de la voie orale, les concentrations sériques obtenues grâce aux préparations orales, la source des données pharmacocinétiques, les résultats cliniques, la prestation des soins à l'unité des soins intensifs, la peur de l'échec thérapeutique et l'administration des antimicrobiens par sonde gastrique.

Conclusions : Lorsque l'on envisage de passer à un traitement par voie orale, il est important de posséder une connaissance approfondie des principaux aspects de l'agent antimicrobien, de l'état du patient et de la maladie traitée. L'équipe de gestion responsable des antimicrobiens détient un rôle important pour ce qui est de simplifier le passage d'une administration intraveineuse à une administration orale, d'éduquer les prescripteurs et de répondre aux préoccupations et doutes qui pourraient faire obstacle à un tel passage en temps voulu.

Mots clés : antimicrobiens, programmes de gestion responsable des antimicrobiens, passage, transition d'une administration intraveineuse à une administration orale, traitement par voie orale, traitement par voie intraveineuse 


\section{INTRODUCTION}

$\mathrm{M}$

any tertiary care hospitals, community-based hospitals, and long-term care facilities are in the process of instituting antimicrobial stewardship programs. A simple, well-recognized intervention that such programs can implement is to change the route of administration of antimicrobial agents from intravenous to oral (IV to PO), provided the oral route is suitable for the patient. Not only does IV to PO conversion benefit the patient, but it is also cost-saving for the institution. ${ }^{1,2}$

Terms commonly used to refer to changing the route from IV to PO include IV to PO transition, IV to PO conversion, IV to PO switch, sequential therapy, or step-down therapy. Throughout this document, we refer to sequential and step-down therapy defined as follows. Generally speaking (although this distinction is not universally applied), sequential therapy refers to a change from an IV version of a medication to its oral counterpart (e.g., IV levofloxacin to oral levofloxacin), whereas step-down therapy refers to a change from an IV version of a medication to an oral agent that may not be therapeutically equivalent (e.g., ceftriaxone to oral cefuroxime or IV cefuroxime to oral cefuroxime). ${ }^{3,4}$

Regardless of the type of change being considered, it is important to have a thorough understanding of key aspects of the antimicrobial agent, the patient, and the disease being treated to best determine whether and when to use an oral antimicrobial and which antimicrobial to select. ${ }^{5,6}$ Key aspects of the antimicrobial agent include its bioavailability, penetration to the site of infection, and spectrum of activity. Regarding the spectrum of activity, provided the organism isolated is susceptible, the oral agent selected does not necessarily need to be the same drug or even in the same class as the IV therapy. For example, for pyelonephritis caused by a susceptible strain of Escherichia coli, it would be appropriate to change IV piperacillin-tazobactam to an oral fluoroquinolone. As another example, IV echinocandin could be changed to oral fluconazole if Candida albicans has been isolated. Key aspects of the patient include immune status, age, allergies, comorbidities, adherence to therapy, ability to absorb and tolerate oral medications, and clinical response. If therapy is changed from IV to oral, the clinician should continue to closely monitor oral tolerability and clinical response. Regarding the disease being treated, factors to consider include the identified or suspected pathogens (and if culture results are not available, the oral agent $[\mathrm{s}]$ selected should provide adequate coverage for the most likely pathogens), local resistance patterns, presence of foreign bodies, and severity of illness. Although milder infections may be treated with oral therapy, parenteral therapy is recommended, at least initially, for more severe, life-threatening, or deep-seated infections, because of concerns about and consequences of inadequate antimicrobial levels at the site of infection. ${ }^{6}$ However, oral antimicrobials that are typically very well absorbed have been used as initial therapy in certain situations. $^{7,8}$
Unfortunately, no universally accepted definitions exist to describe the level of severity of an infection. Often, the degree of severity is defined according to the type of infection and may vary depending on who has established the definitions. For example, the 2014 guidelines on skin and soft-tissue infection of the Infectious Diseases Society of America' ${ }^{9}$ differentiate between mild and moderate infections on the basis of absence or presence of systemic signs of infection, whereas in community-acquired pneumonia, severity is determined by severity-of-illness scores (e.g., CURB-65 [where CURB refers to confusion, uremia, respiratory rate, low blood pressure, and age 65 years or older] or the Pneumonia Severity Index), which are in turn based on presentation and laboratory values. ${ }^{10}$ As such, it is recommended that clinicians refer to guidelines and publications pertaining to the infection that is being treated.

Many institutions have protocols to assist the clinician in deciding when a change from IV to PO therapy may be appropriate. Typical criteria and exclusions used in IV to PO programs are listed in Box 1, but the important principles of IV to PO conversion are beyond the scope of this article, and the reader is referred to additional resources for information about these principles. ${ }^{3,11}$

Despite the existence of protocols and guidelines, an institution's antimicrobial stewardship team may be faced with a number of concerns raised by the attending health care team when a transition from IV to PO therapy is suggested. The concerns most frequently encountered by the authors' antimicrobia

\section{Box 1. Common Criteria for Switch from Intravenous to Oral Administration ${ }^{3,11,12}$}

\section{Inclusion criteria}

- Hemodynamic stability

- Patient is clinically improving (e.g., afebrile or reduction in temperature, normalizing WBC count)

- Functional Gl tract (tolerating food, feeds, other oral medications)

- Ability to swallow or deliver drug via NG or feeding tube

\section{Exclusion criteria}

- Life-threatening or deep-seated infection* (e.g., severe sepsis or septic shock, CNS infections, endocarditis, endophthalmitis, bone and joint infections, vertebral or deep abscesses, necrotizing fasciitis, Staphylococcus aureus bacteremia)

- Neutropenia

- Potential for malabsorption (e.g., continuous NG suction; severe or persistent nausea, vomiting, or diarrhea; ileus or Gl obstruction; active GI bleeding; short bowel syndrome; drug interactions that may affect absorption)

CNS = central nervous system, $\mathrm{Gl}=$ gastrointestinal, NG = nasogastric, $W B C=$ white blood cell.

*Depending on the antimicrobial and the stage of infection, transition to oral therapy may be considered in certain circumstances. Consultation with an infectious diseases specialist is recommended. 
stewardship team are listed and discussed here. The purpose of this review was to provide insight to help stewardship clinicians to assess the validity of these concerns and appropriately address them. A literature search was conducted using Ovid MEDLINE (Ovid Technologies Inc) for the period 1990 to January 2014 (limited to studies involving human adults and published in English) for indexed and non-indexed journals, using the following search strategy: (step down or switch or conversion or transition or sequential) and (antibiotics or antibacterial agents or antimicrobial or anti-infective agents). From the total of 1077 publications identified, key articles were selected to help address the concerns identified. This review is not intended to be a systematic review.

\section{SEVEN CONCERNS ABOUT IV TO PO CONVERSION}

\section{Concern 1: There are no significant benefits to changing from IV to PO administration}

Many practitioners are not aware of all the advantages of changing therapy from IV to PO, which include benefits for the patient, the health care team, the hospital, and the environment. These benefits are summarized in Box 2 .

\section{Concern 2: The oral form does not yield as high serum concentrations as the IV form}

This concern holds true for certain antimicrobial agents but not for others. In the absence of drug interactions, the factors that will affect an agent's serum concentration are its bioavailability, the dose administered, and the patient's ability to absorb and metabolize the medication. Bioavailability, the degree to which an oral formulation is absorbed, is defined as the fraction of a compound that reaches the systemic circulation after administration of a nonparenteral form. ${ }^{21}$ Some antimicrobial agents are reliably absorbed when given orally and thus are highly bioavailable, whereas others are less well absorbed. It can be helpful to think of antimicrobial agents as those whose oral form can provide serum concentration similar to that of the IV counterpart (groups 1 and 2 described in more detail below) and those whose oral form cannot do so (groups 3 and 4 described below).

\section{Group 1: Antimicrobial agents that are well absorbed and well tolerated at doses similar to their respective IV counterparts}

Several antimicrobial agents, such as levofloxacin, moxifloxacin, linezolid, fluconazole, trimethoprim-sulfamethoxazole, and metronidazole, have high bioavailability $(>90 \%) .{ }^{22}$ In addition, their maximum oral dose, which is similar to that of the IV dose, is generally well tolerated. Given the similar drug exposure between the oral form of these agents and their respective IV counterparts, the oral dosage form should provide equal efficacy

\section{Box 2. Potential Benefits of Changing the Route of Administration from Intravenous (IV) to Oral}

\section{For the patient}

Lower risk of adverse events related to IV route:

- Infiltration or extravasation of antimicrobial agent, hematoma, thrombosis, thrombophlebitis ${ }^{13}$

- Catheter-related infections and bacteremia ${ }^{14,15}$

- Pain or discomfort ${ }^{16}$

- Fluid overload in fluid-restricted patients, such as some patients with renal or cardiac disease

Increased ease of mobility ${ }^{16}$

Better quality of life (some patients feel less "medicalized") Earlier discharge from the hospital, ${ }^{17-20}$ thereby decreasing the risk of hospital-acquired infections

\section{For the health care team}

Pharmacy:

- Shorter medication preparation time

Nursing:

- Reduced time required to administer and monitor antimicrobial agents

- No risk of needlestick injuries

\section{For the hospital and the environment}

Lower costs:

- Drug acquisition cost for oral form generally lower than IV form

- Shorter preparation and administration time for antimicrobial agent

- Reduced length of stay

- Reduced rate of hospital-acquired infections

- Saving of "bed-days" from earlier discharge

Reduced waste (e.g., tubing, expired IV bags)

and similar patient outcomes. Provided the patient can absorb the drug and is clinically stable, there is little justification to use the IV route of administration for these drugs. However, in cases of life-threatening or deep-seated infections (e.g., meningitis, endocarditis), IV administration is recommended (Box 1). ${ }^{6}$

\section{Group 2: Antimicrobial agents that are less well absorbed, but whose lower bioavailability can be compensated for by increasing the oral dose}

The bioavailability of ciprofloxacin is good, although lower $(70 \%-80 \%)$ than that of the antimicrobials in group 1 (see above); however, with this drug and some others, the difference in bioavailability can be compensated for by increasing the oral dose. For example, an oral dose of $500 \mathrm{mg}$ of this drug provides drug exposure similar to that of an IV dose of $400 \mathrm{mg}$. Voriconazole is another agent that could fall into this group. Although its product monograph reports a bioavailability of $96 \%$ and recommends IV and oral doses of 3-4 mg/kg IV q12h and $200 \mathrm{mg}$ PO q12h, respectively, ${ }^{23}$ a recently published study showed marked intra- and 
inter-patient variability in voriconazole exposure among patients with invasive fungal infection, with bioavailability of the oral form estimated at $63 \% .{ }^{24}$ This discrepancy was thought to be due to the use of healthy volunteers for determining the bioavailability reported in the monograph, whereas the study population may have had mucositis, vomiting and diarrhea, and differences in food intake that reduced bioavailability. ${ }^{25}$ The authors of the study ${ }^{24}$ concluded that oral doses of 300-400 mg twice daily would be best to achieve desirable therapeutic concentrations. Given this information, it may be prudent to use the higher dosage regimens when converting from IV to orally administered voriconazole, at least in severely immunocompromised patients with invasive fungal disease.

In summary, antimicrobials in groups 1 and 2, for which the oral form can provide serum concentrations and antibiotic exposure similar to those of the IV formulation, may be used initially to treat many non-life-threatening infections, provided the patient is hemodynamically stable and can absorb oral medications. ${ }^{6}$ Otherwise, they can be used as sequential therapy once these conditions are achieved.

\section{Group 3: Antimicrobial agents that are well absorbed but that have a maximum oral dose lower than the maximum of their respective IV counterparts}

For some antimicrobial agents, bioavailability is high, but it is not possible to prescribe an oral dose that would yield a serum concentration similar to that of an IV dose, often because of gastrointestinal intolerance. Examples of these drugs are clindamycin and cephalexin, for which bioavailability is $90 \%$, and amoxicillin, for which bioavailability is $74 \%$ to $92 \%$. $^{22,26}$

\section{Group 4: Antimicrobial agents that are not well absorbed and have a maximum oral dose lower than the maximum of their respective IV counterparts}

The final group consists of antimicrobial agents that have low bioavailability and a recommended maximum oral dose that does not allow sufficient margin for dose increases to compensate for the lower bioavailability. The reason for a lower maximum dose is not always reported, but in certain cases (e.g., cloxacillin) it can be related to poor tolerability.

The lower concentrations achieved with these drugs may be sufficient to treat milder infections or for step-down therapy, but can be problematic for more severe infections. To illustrate the limitations of using these agents in severe infections, consider the example of infective endocarditis due to a strain of penicillinsusceptible viridans group streptococcus. Treatment may require a dose of penicillin $\mathrm{G}$ of up to 24 million units (MU) per day to adequately penetrate the cardiac vegetation and achieve serum concentrations that will exceed the pathogen's minimum inhibitory concentration for a sufficient amount of time to kill the bacteria. However, the oral form, phenoxymethyl penicillin (penicillin VK), is typically prescribed in doses up to $500 \mathrm{mg}$, and occasionally $1 \mathrm{~g}, 4$ times daily (equivalent to 3.2 and 6.4 MU per day, respectively), a significantly lower daily dose than the $24 \mathrm{MU}$ that can be administered by the IV route. ${ }^{22}$ Another example is cefuroxime, a second-generation cephalosporin. A typical IV dose for community-acquired pneumonia is 750 to $1500 \mathrm{mg}$ q $8 \mathrm{~h}$. In contrast, the usual oral dose is $500 \mathrm{mg} \mathrm{q} 12 \mathrm{~h}$ (total daily dose of $1 \mathrm{~g}$ ). In addition to the lower maximum oral dose of these agents, bioavailability must be factored in. The oral form of cefuroxime axetil has a bioavailability of about $40 \%$ to $50 \%$, whereas that of penicillin $\mathrm{V}$ is $66 \%{ }^{22}$ Table 1 compares the IV and oral doses of selected antimicrobials reaching the systemic circulation.

The oral form of the agents in groups 3 and 4 can be prescribed as initial therapy in many mild to moderate infections and as a step-down option (following response to IV therapy) when appropriate in some severe infections. For example, patients with severe cellulitis requiring IV therapy initially may be stepped-down to cephalexin once they are afebrile and local symptoms have improved; similarly, patients with communityacquired pneumonia treated initially with IV $\beta$-lactam antibiotics can be stepped-down to oral agents once they meet certain criteria. ${ }^{9,27}$

The practice of IV to oral step-down for medications in groups 3 and 4 is supported by 2 principles: first, clearance of bacterial infections can be attributed to the combined action of immune defences and antimicrobial agents, and second, when there is a substantial bacterial burden, as at the onset of treatment, high drug concentrations are important to maximize the likelihood of therapeutic success. ${ }^{28,29}$ Thus, once the initial bacterial burden has been reduced sufficiently with IV therapy, oral therapy with group 3 and 4 antibiotics, which yields a lower total serum concentration, may be sufficient.

\section{Concern 3: Bioavailability data are derived from healthy volunteers and therefore do not apply to my patient}

Bioavailability and bioequivalence studies of medications, including antimicrobial agents, are generally conducted in healthy volunteers. ${ }^{30-32}$ Studying the pharmacokinetics and pharmacodynamics of antimicrobial agents in hospital inpatients can indeed be challenging because of the disease process that is present and limitations on obtaining blood for testing. ${ }^{33}$

Despite these barriers, the pharmacokinetics of antimicrobial agents have been characterized in a number of studies, including some involving populations of critically ill, yet stable patients. Some examples are outlined below.

A pharmacokinetic study involving 10 critically ill patients in the intensive care unit (ICU) who were initially started on IV levofloxacin showed that the bioavailability of subsequent oral 
This single copy is for your personal, non-commercial use only.

For permission to reprint multiple copies or to order presentation-ready copies for distribution, contact CJHP at cjhpedit@cshp.ca

\begin{abstract}
Table 1. Comparison of Usual Total Daily Dose* by Intravenous (IV) and Oral Route of Administration for Selected Antimicrobial Agents 22,26
\end{abstract}

Total Daily Dose by Oral Route

\begin{tabular}{|c|c|c|c|}
\hline \multirow[b]{2}{*}{ Medication } & \multirow[b]{2}{*}{$\begin{array}{l}\text { Total Daily Dose } \\
\text { by IV Route }\end{array}$} & \multirow[b]{2}{*}{ Administered } & \multirow[b]{2}{*}{$\begin{array}{c}\text { Reaching Systemic } \\
\text { Circulation (Approximate) }\end{array}$} \\
\hline & & & \\
\hline \multicolumn{4}{|l|}{$\begin{array}{l}\text { High bioavailability and oral dose } \\
\text { similar to IV dose }\end{array}$} \\
\hline Levofloxacin & $0.75 \mathrm{~g}$ & $0.75 \mathrm{~g}$ & $0.75 \mathrm{~g}$ \\
\hline Linezolid & $1.2 \mathrm{~g}$ & $1.2 \mathrm{~g}$ & $1.2 \mathrm{~g}$ \\
\hline \multicolumn{4}{|l|}{$\begin{array}{l}\text { Lower bioavailability that can be } \\
\text { compensated by higher oral dose }\end{array}$} \\
\hline Ciprofloxacin & $0.8 \mathrm{~g}$ & $1 \mathrm{~g}$ & $0.75 \mathrm{~g}$ \\
\hline \multicolumn{4}{|l|}{$\begin{array}{l}\text { High bioavailability and oral dose } \\
\text { lower than IV dose }\end{array}$} \\
\hline Clindamycin & $2.7 \mathrm{~g}$ & $1.8 \mathrm{~g}$ & $1.6 \mathrm{~g}$ \\
\hline Ampicillin (IV) and amoxicillin (oral)‡ & $12 \mathrm{~g}$ & $1.5 \mathrm{~g}$ & $1.2 \mathrm{~g}$ \\
\hline Cefazolin (IV) and cephalexin (oral) $\neq$ & $6 \mathrm{~g}$ & $4 \mathrm{~g}$ & $3.6 \mathrm{~g}$ \\
\hline \multicolumn{4}{|l|}{$\begin{array}{l}\text { Lower bioavailability and oral } \\
\text { dose lower than IV dose }\end{array}$} \\
\hline Penicillin & $24 \mathrm{MU}$ & 6.4 MU & 4.2 MU \\
\hline Cefuroxime & $4.5 \mathrm{~g}$ & $1 \mathrm{~g}$ & $0.45 \mathrm{~g}$ \\
\hline Cloxacillin & $12 \mathrm{~g}$ & $2 \mathrm{~g}$ & $1 \mathrm{~g}$ \\
\hline
\end{tabular}

$\mathrm{MU}=$ million units.

*Presented as upper limit of usual dosage range.

†Taking bioavailability into consideration.

¥In these rows, each dose refers to the pertinent IV or oral form listed in column 1.

levofloxacin was $95 \%$. This level of bioavailability was considered excellent and not statistically different from the $99 \%$ bioavailability reported from healthy volunteers. ${ }^{34}$ Trimethoprimsulfamethoxazole had high bioavailability in 12 critically and non-critically ill men with AIDS who required treatment for Pneumocystis jiroveci pneumonia; the authors concluded that no dosage adjustment appeared necessary when changing the route of administration from IV to oral. ${ }^{35}$ In a study in which IV metronidazole therapy was followed by oral metronidazole therapy, oral bioavailability was $97 \%$ in patients with Crohn disease $(n=7)$ and $90 \%$ in patients with colitis $(n=5) \cdot{ }^{36} \mathrm{~A}$ randomized placebo-controlled trial suggested that fluconazole was well absorbed in critically ill surgical patients. ${ }^{37}$

Some product monographs have reported on the pharmacokinetics of antimicrobials in patients. For example, pharmacokinetic data for the delayed-release tablet formulation of posaconazole showed that the recommended dose achieved the target exposure in $90 \%$ of patients. ${ }^{38}$ The product monograph for voriconazole also indicates that pharmacokinetics have been assessed in patients. Although the characteristics were reportedly similar to those of healthy volunteers, ${ }^{23}$ another study identified lower bioavailability in patients and suggested that the dose be increased. ${ }^{24}$

Although not all permutations of antimicrobial agents and infectious disease processes have been studied, it would be inaccurate to claim that bioavailability studies are conducted only in healthy individuals. Clinicians must also balance this concern against all of the benefits of changing the route of administration from IV to PO, outlined in Box 2.

\section{Concern 4: Patients treated with the IV formulation have better clinical outcomes than patients treated with the oral form}

Some clinicians may be concerned that the oral route of administration is not as efficacious as the IV route. ${ }^{39} \mathrm{~A}$ number of studies have shown similar clinical efficacy for IV therapy and the corresponding sequential or stepped-down therapy, as well as excellent efficacy with oral regimens. For example, in a randomized, double-blind, placebo-controlled multicentre trial, ${ }^{40}$ ciprofloxacin and metronidazole started by the IV route and changed to the oral route had similar high success rates as both the same combination administered intravenously for the full treatment course and imipenem-cilastatin administered intravenously. The criteria for initiating oral therapy were restoration of oral intake and occurrence of an initial clinical response. The study involved adult patients with complicated intra-abdominal infections requiring operative or percutaneous drainage (that is, control of the source of infection), and the change to oral therapy (which occurred between day 3 and day 8) was based on the physician's assessment. ${ }^{40}$ One critique of this study was that for a number of patients (those with milder infections), the course of IV antibiotics administered ( 3 to 5 days) should have been adequate for treatment, and the subsequent oral antibiotics were not necessary. ${ }^{41}$ The practice of transitioning to oral therapy in patients recovering from intra-abdominal infections is also supported by guidelines on this type of infection issued by the Infectious Diseases Society of America, which specify that the patients must be able to tolerate an oral diet and the pathogens must be susceptible to the antimicrobial agents. ${ }^{42}$ 
A recent small prospective randomized study of patients with cellulitis compared the efficacy of oral cephalexin $(1 \mathrm{~g}$ PO 4 times daily; $n=24)$ with that of parenteral cefazolin (2 g IV $\mathrm{q} 12 \mathrm{~h} ; n=23)$ followed by oral cephalexin after clinical improvement was observed. ${ }^{43}$ Patients with mild cellulitis (i.e., limited area and no systemic symptoms) or complicated cellulitis (e.g., accompanied by severe sepsis or abscess) were excluded. The average ages were 48 and 45 years for the groups treated with oral and parenteral therapy, respectively. In both groups, the total duration of treatment was 10 days, and most patients $(n=41)$ were managed at home. The mean time to no advancement of cellulitis was 1.29 days and 1.78 days for the oral and parenteral arms, respectively, with a mean difference of -0.49 day $(95 \%$ confidence interval -1.02 to +0.04 ), which indicates that the oral treatment was noninferior to the parenteral one. The rates of treatment failure and pain, the overall rate of complications, and patient satisfaction were similar in the 2 arms. Notably, the cefazolin dose was $2 \mathrm{~g}$ q12h instead of the usual $1-2 \mathrm{~g}$ q $8 \mathrm{~h}$, but nevertheless, treatment was successful with both initial oral therapy and IV to PO regimens. ${ }^{43}$ Another study showed a clinical cure rate of $97 \%$ among women aged 23 to 62 years with uncomplicated pyelonephritis who were treated with oral ciprofloxacin for 7 days. ${ }^{8}$ Approximately $22 \%$ of the patients had bacteremia. Although prescribers could administer a single IV dose at their discretion, this study emphasized that certain severe infections can be well managed with oral antimicrobials. ${ }^{8}$

In a meta-analysis of randomized controlled trials, transition to oral antibiotics within 2 to 4 days appeared to be as effective as continuous IV therapy in hospitalized patients with moderate to severe community-acquired pneumonia. ${ }^{18}$ Finally, a beforeand-after study assessed the impact of a printed checklist on general medical wards to encourage physicians to change IV antibiotics to oral formulations on day 3 of therapy. ${ }^{12}$ Outcomes for a total of 215 treatment episodes during the 4-month intervention phase with use of the checklist were compared with outcomes for 162 episodes of usual care during the 4-month control phase. The patients in the 2 study phases were comparable (e.g., in terms of age, comorbidities, type of infection). The overall duration of antibiotic treatment was similar in the 2 phases, but a $19 \%$ decrease in the number of days of IV therapy was observed in the intervention group $(p=0.001)$. In subgroup analyses, the reduction in days of IV therapy was statistically significant only for patients with respiratory tract infections; the authors hypothesized that this result might have been due to the low numbers of episodes for other types of infections. Despite the reduction in duration of IV therapy, there was no significant difference in rates of patient relapse, hospital readmission, or mortality. ${ }^{12}$

These examples suggest that for many infections (selected intra-abdominal, skin and soft tissue, and urinary tract infections, as well as community-acquired pneumonia), initial treatment with an oral agent or transition to an oral antimicrobial does not compromise clinical response and should be considered when inclusion criteria are met (Box 1) provided no exclusion criteria are present.

A number of conditions, however, have traditionally required IV therapy. This situation may be due to insufficient evidence supporting the efficacy of oral therapy or a risk of significant clinical deterioration should oral dosing not achieve adequate serum concentrations (e.g., suboptimal bioavailability, lack of adherence to therapy). Common examples of these infections are mentioned in Box 1. Although not considered standard practice, the potential for a switch to highly bioavailable oral therapy is suggested by some of the recent literature. For instance, the authors of a recently published review of patients with primary vertebral osteomyelitis ${ }^{44}$ suggested that switching to an oral antibiotic regimen after 2 weeks of IV therapy may be safe for immunocompetent patients if epidural or paravertebral abscesses have been drained, symptoms have improved, and levels of C-reactive protein have decreased. In about $80 \%$ of patients, the oral agent consisted of ciprofloxacin or another quinolone, clindamycin, or both; in $25 \%$ of the patients, rifampin was added. All of these antibiotics have high bioavailability and tissue penetration. Patients with endocarditis, surgical site infection, and vertebral implants were excluded. ${ }^{44}$ In addition, a comprehensive review discussed several oral options for osteomyelitis, ${ }^{45}$ practice guidelines from the Infectious Diseases Society of America suggested that transitioning to oral therapy may be appropriate for patients with prosthetic joint infections, ${ }^{46}$ and the authors of a systematic review concluded, on the basis of a small clinical trial, that oral ciprofloxacin and rifampin could be considered for the treatment of uncomplicated right-sided infective endocarditis caused by Staphylococcus aureus in IV drug users. ${ }^{47}$

\section{Concern 5: My patient is in the ICU}

It is well established that critically ill patients undergo a number of pathophysiological changes that can affect the pharmacokinetics and pharmacodynamics of antimicrobial agents. ${ }^{48} \mathrm{~A}$ decrease in the microvascular circulation, which can eventually lead to multiple organ dysfunction, such as renal and liver failure, can affect the metabolism and elimination of drugs. ${ }^{48}$ In addition, gut hypomotility can occur in sepsis, following surgery, or as a result of the administration of opioids, which in turn can reduce drug absorption. Conversely, gut hypermotility can also occur, affecting the absorption of drugs by decreasing contact time between the drug and the mucosa of the small intestines. The $\mathrm{pH}$ of gastrointestinal tract secretions may be lowered by acidreducing medications, which will affect the dissolution of certain agents. ${ }^{49}$ Certain studies have shown, however, that a patient's mere presence in the ICU does not preclude administration of oral antimicrobials or transition from the IV to the PO route of administration. ${ }^{34,35,37,50}$ 
In a pharmacokinetic study involving 10 patients in the ICU, ${ }^{34}$ levofloxacin $500 \mathrm{mg}$ given intravenously for 3 to 5 days was compared with $500 \mathrm{mg}$ of the same drug given orally to the same patients after completion of the IV therapy. Although the maximum and minimum concentrations were significantly higher with the IV route, the area under the curve for the first $24 \mathrm{~h}$ (an indication of total exposure) was not statistically different, and the median absolute bioavailability was $95 \%$. The majority of patients were treated for community-acquired pneumonia $(n=8)$, had stable renal function, and no gastrointestinal dysfunction before being changed to the oral form. The authors concluded that oral levofloxacin was well absorbed. ${ }^{34}$

In a study in which fluconazole was administered intravenously and orally (crushed and given by feeding tube) to 5 patients in the ICU who had normal gastrointestinal motility and renal and hepatic function, ${ }^{50}$ the bioavailability was approximately $97 \%$. In another study, serum concentrations of fluconazole were monitored in critically ill surgical patients who received fluconazole or placebo enterally for the prevention of fungal infections $(n=121)$; no IV preparation of fluconazole was administered. ${ }^{37}$ The authors concluded that serum levels after enteral fluconazole, including in the immediate postoperative period, were adequate to prevent most Candida infections in this patient population. ${ }^{37}$

Four patients with AIDS were admitted to the ICU and were given trimethoprim-sulfamethoxazole intravenously for treatment of Pneumocystis jiroveci pneumonia, followed by the same dose given orally. ${ }^{35}$ The oral form was well tolerated, with bioavailability of approximately $97 \%$ for the trimethoprim component and $86 \%$ for the sulfamethoxazole component. The authors concluded that dosage adjustment did not appear to be required when changing from IV to oral administration in critically ill patients with AIDS. ${ }^{35}$

Although oral administration of antimicrobials is not contraindicated in the ICU, critically ill patients are more likely to have factors that preclude oral administration of antimicrobial agents of which the pharmacist should be cognizant. For example, one clue suggesting gastrointestinal failure is the need for vasopressors, which may indicate suboptimal gut perfusion and hemodynamic instability. Other clues to possible impaired absorption, which are not necessarily limited to critically ill patients, include food intolerance (e.g., vomiting), intolerance of feeding by nasogastric tube (as suggested by high aspirate volumes), gastrointestinal hemorrhage, or ileus. ${ }^{51}$ As well, patients undergoing chemotherapy and those with severe oral mucositis may have impaired gut function.

The clinical status of patients in the ICU may change rapidly, and it is therefore important to regularly and frequently assess their clinical status and the appropriateness of oral drug administration.

\section{Concern 6: If the infection does not resolve, I will know it's not because of poor antimicrobial absorption}

In certain cases, the risk of treatment failure would be critically detrimental, and the IV route of administration may therefore be warranted. For many infections, however, the oral route of administration is appropriate, and the clinician must consider the disadvantages to giving, or continuing to give, an antimicrobial agent intravenously when it may not be necessary (see Box 2). If the clinical situation is amenable to oral therapy (particularly if a well-absorbed antimicrobial has been prescribed), if the patient is a candidate for oral therapy, and if the patient is expected to be adherent to the treatment regimen, fear of inadequate systemic delivery should not deter the clinician from switching the route of administration.

Therapeutic drug monitoring may be helpful in certain cases, as it is a tool that helps to determine drug exposure and may be used to document adequate absorption. However, this form of monitoring is usually reserved for oral drugs with unpredictable dose exposure, such as the antifungals itraconazole, voriconazole, and posaconazole. ${ }^{52,53}$

\section{Concern 7: My patient has a feeding tube}

Feeding tubes are used to provide nutrition in a variety of situations such as dysphagia, severe reflux, gastroparesis, and chronic nausea or vomiting. ${ }^{54}$ Feeding tubes can deliver enteral nutrition and orally administered medications directly to the stomach, duodenum, or jejunum.

There are a number of potential issues regarding the administration of medications via a feeding tube. The absorption of medications may be altered for a variety of reasons, for example, because of inadequate $\mathrm{pH}$ at the site of delivery, a delivery site beyond the site of absorption, a change in the contact time between the medication and the gastrointestinal tract, adsorption of the drug to the tubing, inadequate flushing of the tube, or an inadequate formulation (e.g., using a ciprofloxacin suspension carries a high risk of tube blockage, ${ }^{55}$ and ciprofloxacin tablets should be crushed instead)..$^{56}$

Another problem that can affect the absorption of a drug involves interactions between drugs or between enteral feeds and a drug. For example, enteral feeding coadministered with ciprofloxacin via a gastrostomy or jejunostomy tube has been shown to decrease the bioavailability of ciprofloxacin by $27 \%$ to $67 \% .{ }^{57}$ No consensus exists on the optimal period for which enteral feeding should be held to minimize such interactions, but holding continuous feeds for at least $1 \mathrm{~h}$ before and $2 \mathrm{~h}$ after quinolone administration has been suggested. ${ }^{58}$ Using the upper limit of a dose range has also been recommended, ${ }^{56,58}$ although the authors of a systematic review on this topic could not draw firm conclusions about the clinical outcome of such a practice. ${ }^{59}$

It is difficult, if not impossible, to account for the impact of all these factors in deciding whether administration via feeding 
This single copy is for your personal, non-commercial use only.

For permission to reprint multiple copies or to order presentation-ready copies for distribution, contact CJHP at cjhpedit@cshp.ca

tube is appropriate for a particular drug. Fortunately, references are available to help fill the gaps in knowledge, and clinicians are generally comfortable administering drugs, including antimicrobials, via feeding tube. A recently updated book collates available data from the literature and manufacturers and provides suggestions and recommendations for administering medications through feeding tubes. ${ }^{56}$ Another reference provides information on the adequacy of absorption via the duodenum and jejunum for several medications, including some antimicrobial agents. ${ }^{54}$

\section{CONCLUSIONS}

Although antimicrobial agents delivered by the IV route are effective, they are associated with numerous disadvantages from the perspective of patients, the health care team, the hospital, and the environment. Prescribers may have concerns related to the use of oral antimicrobials, such as the need to administer via feeding tube, fear of treatment failure because of misconceptions about bioavailability or treatment outcomes, the patient's presence in the ICU, or simply lack of familiarity with the risks associated with IV administration. The antimicrobial stewardship team can play an important role in assessing the validity of these concerns as they apply to individual patients and educating prescribers when the concerns do not apply.

\section{References}

1. Goff DA, Bauer KA, Reed EE, Stevenson KB, Taylor JJ, West JE. Is the "low-hanging fruit" worth picking for antimicrobial stewardship programs? Clin Infect Dis. 2012;55(4):587-92.

2. Lau BD, Pinto BL, Thiemann DR, Lehmann CU. Budget impact analysis of conversion from intravenous to oral medication when clinically eligible for oral intake. Clin Ther. 2011;33(11):1792-6.

3. Kuper K. Intravenous to oral therapy conversion. In: Murdaugh LB. Competence assessment tools for health-system pharmacies. 4 th ed. Bethesda (MD): American Society of Health-System Pharmacists; 2008. p. 347-60.

4. Lelekis M, Gould IM. Sequential antibiotic therapy for cost containment in the hospital setting: why not? J Hosp Infect. 2001;48(4):249-57.

5. Burgess D. Antimicrobial regimen selection. In: DiPiro JT, Talbert RL, Yee GC, Matzke GR, Wells BG, Posey LM, editors. Pharmacotherapy a pathophysiological approach. 8th ed. Toronto (ON): The McGraw-Hills Companies; 2011. p. 1813-23.

6. Pillai S, Eliopoulos G, Moellering R. Principles of anti-infective therapy. In: Mandell G, Bennett J, Dolin R, editors. Principles and practice of infectious diseases. 7th ed. Philadelphia (PA): Churchill Livingston Elsevier; 2010. p. 267-78.

7. Itani KM, Biswas P, Reisman A, Bhattacharyya H, Baruch AM. Clinical efficacy of oral linezolid compared with intravenous vancomycin for the treatment of methicillin-resistant Staphylococcus aureus-complicated skin and soft tissue infections: a retrospective, propensity score-matched, case-control analysis. Clin Ther. 2012;34(8):1667-73.

8. Sandberg T, Skoog G, Hermansson AB, Kahlmeter G, Kuylenstierna N, Lannergard A, et al. Ciprofloxacin for 7 days versus 14 days in women with acute pyelonephritis: a randomised, open-label and double-blind, placebocontrolled, non-inferiority trial. Lancet. 2012;380(9840):484-90.

9. Stevens DL, Bisno AL, Chambers HF, Dellinger EP, Goldstein EJ, Gorbach SL, et al. Practice guidelines for the diagnosis and management of skin and soft tissue infections: 2014 update by the Infectious Diseases Society of America. Clin Infect Dis. 2014;59(2):e10-e52.

10. Mandell LA, Wunderink RG, Anzueto A, Bartlett JG, Campbell GD, Dean NC, et al. Infectious Diseases Society of America/American Thoracic Society consensus guidelines on the management of community-acquired pneumonia in adults. Clin Infect Dis. 2007;44 Suppl 2:S27-S72.
11. Barlow GD, Nathwani D. Sequential antibiotic therapy. Curr Opin Infect Dis. 2000;13(6):599-607.

12. Mertz D, Koller M, Haller P, Lampert ML, Plagge H, Hug B, et al. Outcomes of early switching from intravenous to oral antibiotics on medical wards. J Antimicrob Chemother. 2009;64(1):188-99.

13. Fraser Health Vascular Access Regional Shared Work Team; Hignell P. Peripheral intravenous initiation: selflearning module. Version 5. Surrey (BC): Fraser Health; 2012 May [cited 2014 Aug 13]. Available from: https://www.fraserhealth.ca/media/PeripheralIntravenousInitiation Module.pdf

14. Rojo D, Pinedo A, Clavijo E, Garcia-Rodriguez A, Garcia V. Analysis of risk factors associated with nosocomial bacteraemias. J Hosp Infect. 1999; 42(2):135-41.

15. Safdar N, Maki DG. Risk of catheter-related bloodstream infection with peripherally inserted central venous catheters used in hospitalized patients. Chest. 2005;128(2):489-95.

16. Bamford KB, Desai M, Aruede MJ, Lawson W, Jacklin A, Franklin BD. Patients' views and experience of intravenous and oral antimicrobial therapy: room for change. Injury. 2011;42 Suppl 5:S24-S7.

17. Carratala J, Garcia-Vidal C, Ortega L, Fernandez-Sabe N, Clemente M, Albero G, et al. Effect of a 3-step critical pathway to reduce duration of intravenous antibiotic therapy and length of stay in community-acquired pneumonia: a randomized controlled trial. Arch Intern Med. 2012; 172(12):922-8.

18. Athanassa Z, Makris G, Dimopoulos G, Falagas ME. Early switch to oral treatment in patients with moderate to severe community-acquired pneumonia: a meta-analysis. Drugs. 2008;68(17):2469-81.

19. Oosterheert JJ, Bonten MJM, Schneider MME, Buskens E, Lammers JW, Hustinx WMN, et al. Effectiveness of early switch from intravenous to oral antibiotics in severe community acquired pneumonia: multicentre randomised trial. BMJ. 2006;333(7580):1193.

20. Desai M, Franklin BD, Holmes AH, Trust S, Richards M, Jacklin A, et al. A new approach to treatment of resistant gram-positive infections: potential impact of targeted IV to oral switch on length of stay. BMC Infect Dis. 2006;6:94.

21. Fan J, de Lannoy IAM. Pharmacokinetics. Biochem Pharmacol. 2014; 87(1):93-120.

22. Lexicomp Online ${ }^{\circledR}$, Lexi-Drugs ${ }^{\circledR}$ [database on Internet]. Hudson $(\mathrm{OH})$ : Lexicomp Inc; (C)1978-2014 [cited 2014 Aug 14]. Available from: www.lexi.com/. Registration required to access content.

23. Voriconazole product monograph. Kirkland (QC): Pfizer Canada Inc; 2014 Oct 30 .

24. Pascual A, Csajka C, Buclin T, Bolay S, Bille J, Calandra T, et al. Challenging recommended oral and intravenous voriconazole doses for improved efficacy and safety: population pharmacokinetics-based analysis of adult patients with invasive fungal infections. Clin Infect Dis. 2012;55(3):381-90.

25. Andes D, Lepak A. Editorial commentary: Antifungal therapeutic drug monitoring progress: getting it right the first time. Clin Infect Dis. 2012;55(3):391-3.

26. AHFS drug information ${ }^{\circledR}$ [database on Internet]. Bethesda (MD): American Society of Health-System Pharmacists, Inc: (C1959-2014 [cited 2014 Aug 14]. Available from: www.ahfsdruginformation.com/. Registration required to access content.

27. Swartz MN. Clinical practice. Cellulitis. New Engl J Med. 2004;350(9):904-12.

28. Ankomah P, Levin BR. Exploring the collaboration between antibiotics and the immune response in the treatment of acute, self-limiting infections. Proc Natl Acad Sci US A. 2014;111(23):8331-8.

29. Martinez MN, Papich MG, Drusano GL. Dosing regimen matters: the importance of early intervention and rapid attainment of the pharmacokinetic/pharmacodynamic target. Antimicrob Agents Chemother. 2012;56(6): 2795-805.

30. Azithromycin product monograph. Mississauga (ON): Actavis Pharma Company; 2014 Oct 22.

31. Cefuroxime axetil product monograph. Mississauga (ON): GlaxoSmith Kline Inc; 2014 Jan 30.

32. Guidance for industry. Bioavailability and bioequivalence studies submitted in NDAs or INDs-general considerations. Draft guidance. Rockville 
This single copy is for your personal, non-commercial use only.

For permission to reprint multiple copies or to order presentation-ready copies for distribution, contact CJHP at cjhpedit@cshp.ca

(MD): US Department of Health and Human Services, Food and Drug Administration, Center for Drug Evaluation and Research; 2014 [cited 2014 Feb 3]. Available from: www.fda.gov/downloads/drugs/ guidancecomplianceregulatoryinformation/guidances/ucm389370.pdf

33. Drusano GL. Pharmacokinetics and pharmacodynamics of antimicrobials. Clin Infect Dis. 2007;45 Suppl 95:S89-S95.

34. Rebuck JA, Fish DN, Abraham E. Pharmacokinetics of intravenous and oral levofloxacin in critically ill adults in a medical intensive care unit. Pharmacotherapy. 2002;22(10):1216-25.

35. Chin TW, Vandenbroucke A, Fong IW. Pharmacokinetics of trimethoprimsulfamethoxazole in critically ill and non-critically ill AIDS patients. Antimicrob Agents Chemother. 1995;39(1):28-33.

36. Shaffer JL, Kershaw A, Houston JB. Disposition of metronidazole and its effects on sulphasalazine metabolism in patients with inflammatory bowel disease. Br J Clin Pharmacol. 1986;21(4):431-5.

37. Pelz RK, Lipsett PA, Swoboda SM, Merz W, Rinaldi MG, Hendrix CW. Enteral fluconazole is well absorbed in critically ill surgical patients. Surgery. 2002;131(5):534-40.

38. Posaconazole product monograph. Kirkland (QC): Merck Canada Inc; 2014 Oct 20.

39. Vanstraelen K, Verhaegen J, Peetermans WE, Willems L, Spriet I. Stimulation of the i.v. to oral switch of bioavailable drugs by phone calls in a Belgian tertiary care hospital. Acta Clin Belg. 2013;68(3):179-82.

40. Solomkin JS, Reinhart HH, Dellinger EP, Bohnen JM, Rotstein OD, Vogel $\mathrm{SB}$, et al. Results of a randomized trial comparing sequential intravenous/oral treatment with ciprofloxacin plus metronidazole to imipenem/cilastatin for intra-abdominal infections. The Intra-Abdominal Infection Study Group. Ann Surg. 1996;223(3):303-15.

41. Davey P, Nathwani D. Sequential antibiotic therapy: the right patient, the right time and the right outcome. J Infect. 1998;37 Suppl 1:37-44.

42. Solomkin JS, Mazuski JE, Bradley JS, Rodvold KA, Goldstein EJ, Baron EJ, et al. Diagnosis and management of complicated intra-abdominal infection in adults and children: guidelines by the Surgical Infection Society and the Infectious Diseases Society of America. Clin Infect Dis. 2010; 50(2):133-64

43. Aboltins CA, Hutchinson AF, Sinnappu RN, Cresp D, Risteski C, Kathirgamanathan $\mathrm{R}$, et al. Oral versus parenteral antimicrobials for the treatment of cellulitis: a randomized non-inferiority trial. J Antimicrob Chemother. 2015;70(2):581-6.

44. Babouee FB, Elzi L, Kolbe M, Frei R, Weisser M, Scharen S, et al. Is switching to an oral antibiotic regimen safe after 2 weeks of intravenous treatment for primary bacterial vertebral osteomyelitis? BMC Infect Dis. 2014;14:226.

45. Spellberg B, Lipsky BA. Systemic antibiotic therapy for chronic osteomyelitis in adults. Clin Infect Dis. 2012;54(3):393-407.

46. Osmon DR, Berbari EF, Berendt AR, Lew D, Zimmerli W, Steckelberg JM, et al. Executive summary: diagnosis and management of prosthetic joint infection: clinical practice guidelines by the Infectious Diseases Society of America. Clin Infect Dis. 2013;56(1):1-10.

47. Al-Omari A, Cameron DW, Lee C, Corrales-Medina VF. Oral antibiotic therapy for the treatment of infective endocarditis: a systematic review. BMC Infect Dis. 2014;14:140.

48. Roberts JA, Lipman J. Pharmacokinetic issues for antibiotics in the critically ill patient. Crit Care Med. 1998;37(3):840-51.

49. Power BM, Forbes AM, van Heerden PV, Ilett KF. Pharmacokinetics of drugs used in critically ill adults. Clin Pharmacokinet. 1998;34(1):25-56.

50. Nicolau DP, Crowe H, Nightingale CH, Quintiliani R. Bioavailability of fluconazole administered via a feeding tube in intensive care unit patients. J Antimicrob Chemother. 1995;36(2):395-401.
51. Reintam A, Parm P, Redlich U, Tooding LM, Starkopf J, Kohler F, et al. Gastrointestinal failure in intensive care: a retrospective clinical study in three different intensive care units in Germany and Estonia. BMC Gastroenterol. 2006;6:19.

52. Andes D, Pascual A, Marchetti O. Antifungal therapeutic drug monitoring established and emerging indications. Antimicrob Agents Chemother. 2009, 53(1):24-34

53. Laverdiere M, Bow EJ, Rotstein C, Autmizguine J, Broady R, Garber G, et al. Therapeutic drug monitoring for triazoles: a needs assessment review and recommendations from a Canadian perspective. Can J Infect Dis Med Microbiol. 2014;25(6):327-43.

54. McIntyre CM, Monk HM. Medication absorption considerations in patients with postpyloric enteral feeding tubes. Am J Health Syst Pharm. 2014;71(7):549-56.

55. Beckwith MC, Feddema SS, Barton RG, Graves C. A guide to drug therapy in patients with enteral feeding tubes: dosage form selection and administration methods. Hosp Pharm. 2004;39(3):225-37.

56. White R, Bardnam V. Handbook of drug administation via enteral feeding tubes. 2nd ed. London (UK): Pharmaceutical Press; 2011

57. Healy DP, Brodbeck MC, Clendening CE. Ciprofloxacin absorption is impaired in patients given enteral feedings orally and via gastrostomy and jejunostomy tubes. Antimicrob Agents Chemother. 1996;40(1):6-10.

58. Williams NT. Medication administration through enteral feeding tubes. Am J Health Syst Pharm. 2008;65(24):2347-57.

59. Chui D, Cheng L, Tejani AM. Clinical equivalency of ciprofloxacin $750 \mathrm{mg}$ enterally and $400 \mathrm{mg}$ intravenously for patients receiving entera feeding: systematic review. Can J Hosp Pharm. 2009;62(2):127-34.

Lizanne Béïque, BPharm, PharmD, is a Clinical Pharmacy Specialist for the Antimicrobial Stewardship Program, Pharmacy Department, The Ottawa Hospital, and a Clinical Investigator with the Ottawa Hospital Research Institute, Ottawa, Ontario.

Rosemary Zvonar, BScPhm, ACPR, FCSHP, is currently Antimicrobial Stewardship Program Lead with Public Health Ontario (on leave from her position as Antimicrobial Pharmacy Specialist with the Pharmacy Department, The Ottawa Hospital, Ottawa, Ontario.)

Competing interests: Lizanne Béïque (primary and corresponding author) received a small honorarium from Merck Frosst for facilitating a presentation on therapeutic drug monitoring of azoles. No other competing interests were declared.

\section{Address correspondence to:}

Dr Lizanne Béïque

Pharmacy Department

The Ottawa Hospital, General Campus

501 Smyth Road

Ottawa ON K1H 8 L6

e-mail: Ibeique@toh.on.ca

Funding: No financial support was received for the preparation and writing of this manuscript. 